\title{
Efeito do Dia de Ocupação sobre a Produção Leiteira de Vacas Mestiças em Pastejo Rotacionado de Forrageiras Tropicais ${ }^{1}$
}

\author{
Andréa Luciana dos Santos ${ }^{2}$, Maria Lúcia Pereira Lima ${ }^{3}$, Telma Teresinha Berchielli ${ }^{4}$, Paulo \\ Roberto Leme ${ }^{5}$, Euclides Braga Malheiros ${ }^{4}$, José Ramos Nogueira ${ }^{3}$, Maria da Graça Pinheiro ${ }^{3}$, \\ Nilson Carlos Lima6 ${ }^{6}$, Flávia Fernanda Simili²
}

\begin{abstract}
RESUMO - O trabalho foi conduzido para se observar as flutuações na produção leiteira de vacas mestiças em sistema de pastejo rotacionado de capim-elefante cv. Guaçu (Pennisetum purpureum Schum.) e capim-tanzânia (Panicum maximum Jacq.), de acordo com períodos de ocupação (dois dias de ocupação e 40 de descanso e três dias de ocupação e 33 de descanso, respectivamente), adubados com $200 \mathrm{~kg}$ de N/ha/ano. Foram estudados 19 piquetes de capim-elefante e 15 de capim-tanzânia. A análise estatística foi realizada considerandose fase de lactação das vacas, piquete e dia de ocupação. Para o capim-elefante houve efeito da fase da lactação com interação com o dia de ocupação, mas não houve diferença para o dia de ocupação. As médias foram 10,3 $\pm 3,3$ e 10,4 $\pm 3,2 \mathrm{~kg}$ de leite/vaca/dia para o $1^{\circ} \mathrm{e}$ $2^{\circ}$ dia de ocupação, respectivamente. Para o capim-tanzânia, houve diferença significativa na produção de leite, conforme o dia de ocupação, e interação significativa para piquete e dia de ocupação. As médias foram 10,6 $\pm 3,0 ; 11,0 \pm 3,1 ; 10,6 \pm 3,2 \mathrm{~kg}$ de leite/vaca/dia, respectivamente, para o primeiro, segundo e terceiro dias de ocupação.
\end{abstract}

Palavras-chave: capim-elefante, capim-tanzânia, Panicum maximum Jacq, Pennisetum purpureum Schum

\section{Days of Occupation on Crossbred Cows Milk Production in a Rotational Grazing System Tropical}

\begin{abstract}
The study was carried out to observe the fluctuation of milk yield of crossbred cows in two rotational grazing systems of elephant grass cv. Guaçu (Pennisetum purpureum Schum and Tanzaniagrass (Panicum maximum Jacq.), according of period of occupation ( 2 days of occupation with 40 days resting and 3 days of occupation with 33 days resting, respectively), fertilized with $200 \mathrm{~kg}$ of N/ha/year. Nineteen paddocks of elephantgrass and 15 of Tanzaniagrass were studied. The statistical analysis was performed considering lactation phase of cows, paddocks and days of occupation. For elephantgrass there was an interaction effect of lactation phase and days of occupation, but no difference was observed for days of occupation. Averages of daily milk yield were $10.3 \pm 3.3$ and $10.4 \pm 3.2 \mathrm{~kg} /$ day for $1^{\text {st }}$ and $2^{\text {nd }}$ of days of occupation, respectively. For Tanzaniagrass there was a significant effect for milk yield, according to days of occupation and for interaction of paddocks and days of occupation. The averages of daily milk yield were $10.6 \pm 3.0 ; 11.0 \pm 3.1 ; 10.6 \pm 3.16 \mathrm{~kg} / \mathrm{cow} /$ day for $1^{\text {st }}, 2^{\text {nd }}$ and $3^{\text {rd }}$ days of occupation, respectively.
\end{abstract}

Key Words: elephantgrass, Panicum maximum Jacq, Pennisetum purpureum Schum, Tanzaniagrass

\section{Introdução}

O uso de sistemas de pastejo rotacionado tem aumentado em fazendas destinadas à produção leiteira, no intuito de melhorar a qualidade da forragem ofertada aos animais e aumentar a lotação, reduzindo os custos de produção. Mesmo assim, muitas dúvidas acerca do manejo adequado e de suas conseqüências precisam ser esclarecidas.
Segundo Corsi (1994), no Brasil, parece que a necessidade de conhecimento básico para o estudo e a execução de sistemas de manejo das pastagens impõe-se de maneira muito lenta, em virtude de dispormos, nos trópicos, de uma infinidade de estratégias para produção e uso das plantas forrageiras.

Outras dificuldades, como problemas sanitários, custo dos insumos, plantas forrageiras de baixa qualidade e o desfavorecimento do clima tropical, geram

\footnotetext{
${ }^{1}$ Projeto financiado pela FAPESP.

2 Aluna do curso de Pós-graduação em Zootecnia/FCAV/UNESP/Jaboticabal . End. Correspondência: Rua Prof. Paulo Mont Serrat, n501, JD Ricetti - São Carlos - CEP: 14870-240 (andrealsfia@ig.com.br).

3 Pesquisador Científico do Instituto de Zootecnia, AV: Bandeirantes 2419 - $14030-670$, Ribeirão Preto, SP (marialucia@aptaregional.sp.gov.br).

4 Professor da FCAV - Unesp - 14870-000 - Jaboticabal, SP (ttberchi@fcav.unesp.br; euclides@fcav.unesp.br).

5 Professor da FZEA/ USP - 13630-000 - Pirassununga, SP (prleme@usp.br).

6 Zootecnista formado na FCAV - Unesp- 14870-000 Jaboticabal, SP.
} 
dificuldades que poderiam ser revertidas com o uso de tecnologias apropriadas, que alteram significativamente os índices de produtividade e o retorno financeiro (Camargo, 1996).

Entre as gramíneas tropicais, o capim-elefante destaca-se pela alta produtividade e qualidade de forragem produzida. Sua utilização sob a forma de pastejo é recente e os resultados têm comprovado excelente potencial para produção animal, inclusive na produção leiteira (Deresz \& Mozzer, 1990; Veiga, 1990; Corsi, 2000).

Vários estudos indicam que vacas mantidas em pastagens de capim-elefante podem produzir de 8 a 14 $\mathrm{kg}$ de leite/dia, dependendo do potencial de produção e do estádio de lactação das vacas, assim como da lotação utilizada (Lucci et al.,1969; Lucci et al., 1972; Veloso \& Freitas, 1973; Deresz \& Mozzer, 1990; Olivo et al., 1992; Cóser et al., 1999; Aroeira et al., 1999).

Segundo Aranovich (1995), a gramínea Panicum maximum é uma das principais forrageiras cultivadas no Brasil, ocupando, inclusive, área superior a seis milhões de hectares. Na década de 70 , representou cerca de $32 \%$ da área total de pastagens do estado de São Paulo. Sua introdução, uma vez que é de origem africana, não está bem esclarecida, mas atribui-se sua chegada à importação de escravos africanos, estabelecendo-se nos lugares onde os navios eram descarregados. Porém, embora se reconheça seu potencial produtivo, há informações de que as áreas de Panicum no país estejam decrescendo, cedendo lugar às gramíneas do gênero Brachiaria, sobretudo em razão da exigência em boa fertilidade do solo e do manejo inadequado.

Recentemente, este quadro vem se revertendo em função de novos cultivares, inclusive o capimtanzânia, mais produtivo que o capim-colonião (Euclides, 1995).

Teixeira et al. (1999), trabalhando com capimtobiatã (Panicum maximum Schum. cv. Tobiatã), na EMBRAPA de São Carlos, avaliaram a produção de leite de vacas holandesas com 72 dias de lactação, manejadas de forma que ingerissem apenas as pontas das folhas e que o restante da forragem fosse consumido por animais de repasse. A média de produção de leite por vaca, no início da lactação, foi de $30,6 \mathrm{~kg} / \mathrm{dia}$; o concentrado foi oferecido na proporção de $1 \mathrm{~kg}$ para 2,8 de leite, ou seja, a média de consumo de concentrado foi de $11 \mathrm{~kg} /$ dia. No entanto, publicações sobre a produção de leite de vacas mantidas em capimtanzânia não têm sido encontradas.
Trabalhos realizados no exterior, avaliando o potencial de produção de leite em Panicum maximum indicaram produção diária de leite de 9,5 a $10,7 \mathrm{~kg} /$ vaca (Davison et al., 1985a;b).

No sistema de pastejo rotacionado, o produtor deve conhecer as flutuações na produção diária das vacas leiteiras, relacionadas à ocupação de cada piquete (Deresz, 1994). Cóser et al. (1999) estudaram as oscilações na produção de leite em pastejo rotacionado de capim-elefante com 1, 3 e 5 dias de ocupação e encontraram menores flutuações para um dia de ocupação e maiores para cinco dias de ocupação, mas não encontraram interações que pudessem afetar a produção leiteira.

Objetivou-se observar a influência do dia de ocupação dos piquetes sobre a variação na produção de leite de vacas mestiças em diferentes fases de lactação, em sistema de pastejo rotacionado de capim-elefante cv. Guaçu (Pennisetum purpureum Schum.) e de capim-tanzânia (Panicum maximum Jacq.). Também foram estudadas possíveis interações entre as fases de lactação das vacas e o dia de ocupação avaliado, em cada planta forrageira.

\section{Material e Métodos}

O trabalho foi conduzido no Núcleo de Pesquisas Zootécnicas Nordeste, do Instituto de Zootecnia de Ribeirão Preto, SP, localizado na latitude sul $21^{\circ} 42^{\prime}$, longitude oeste $47^{\circ} 24^{\prime}$, com altitude de 435 metros. O soloé um latossolo roxo distrófico, levemente ondulado.

O clima é classificado como CWA, com verões quentes e chuvosos e invernos secos. Os valores referentes à temperatura ambiente média, assim como as informações de precipitação pluviométrica, foram anotados diariamente e são apresentados na Figura 1.

Foram conduzidos dois experimentos distintos, um em pastejo rotacionado com capim-elefante cv. Guaçu (Pennisetum purpureum Schum.) e o outro em área com capim-tanzânia (Panicum maximum Jacq.).

As massas de forragem disponível inicial e residual foram avaliadas, nos dois experimentos, por ciclo de pastejo, utilizando-se quadrado $2 \times 2 \mathrm{~m}$ em quatro piquetes com três repetições, das quais foram feitas subamostragens e separação em colmo, folha e material morto. No primeiro ano experimental, as avaliações das pastagens foram feitas por Rosseto (2000). Antes de se iniciar o estudo, cada área recebeu em cobertura aplicações de calcário, adubos fosfatado, potássico e micronutrientes. Durante as amostragens, 


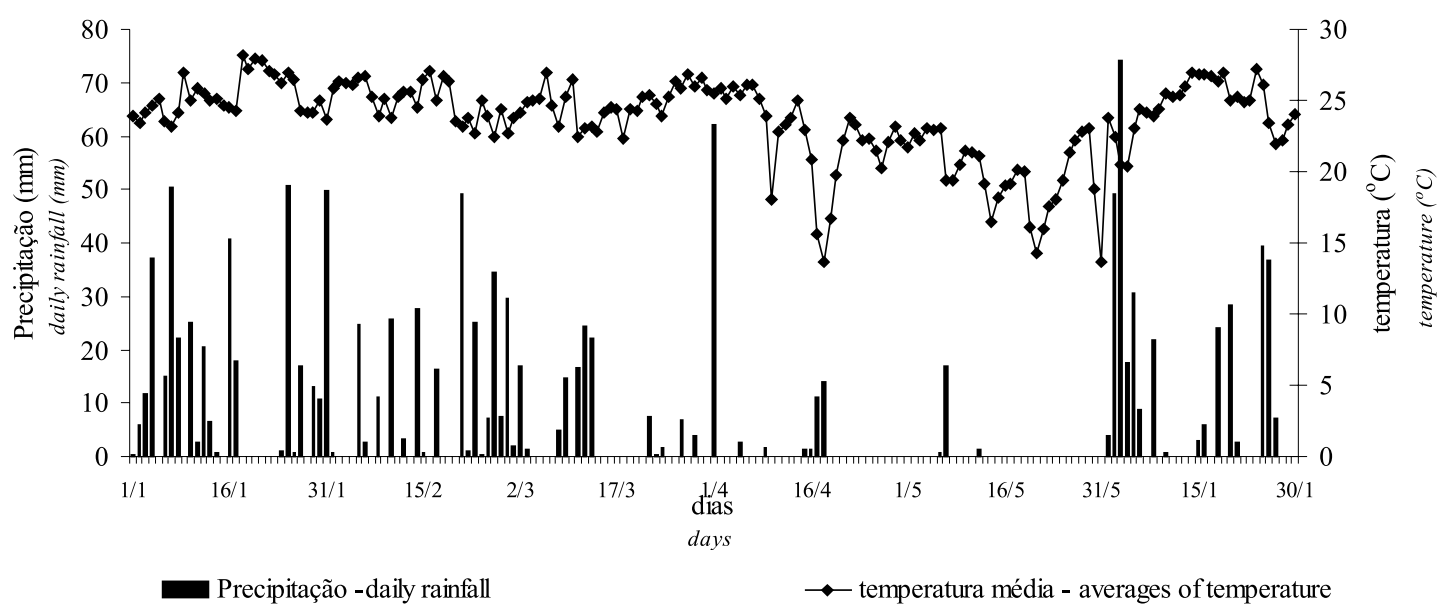

Figura 1 - Precipitação (mm) e temperaturas médias diárias $\left({ }^{\circ} \mathrm{C}\right)$ de janeiro a maio de 1999 e janeiro de 2000. Figure 1 - Daily rainfall $(\mathrm{mm})$ and averages of temperature $\left({ }^{\circ} \mathrm{C}\right)$ from January to May 1999 and January 2000.

foram aplicados $250 \mathrm{~kg}$ de N/ha/ano, em cada sistema de pastejo rotacionado.

A área de capim-elefante, em uso há oito anos, possuía 10,5 ha, subdivididos em 21 piquetes, utilizados com período de ocupação de dois dias e descanso de 40 dias. O capim-elefante foi manejado em quatro ciclos de pastejo em cada ano experimental. A produção de leite foi avaliada do $2^{\circ}$ ao $4^{\circ}$ ciclo de pastejo de 1999 , em 16 piquetes e, no $1^{\circ}$ ciclo de pastejo do ano 2000, em três piquetes.

A área de capim-tanzânia era utilizada há cinco anos e constava de 15,8 ha, subdivididos em 12 piquetes, utilizados com período de ocupação de três dias e 33 dias de descanso, perfazendo cinco ciclos de pastejo por ano. A produção de leite foi avaliada do $2^{\circ}$ ao $4^{\circ}$ ciclo de pastejo de 1999 , em 13 piquetes e, no $1^{\circ}$ ciclo de pastejo do ano 2000, foram avaliados dois piquetes.

A produção leiteira foi medida diariamente, em duas ordenhas, utilizando-se, em cada experimento,
12 vacas mestiças Holandês x Gir, no período de fevereiro a maio de 1999 e 15 em janeiro de 2000. Os animais foram classificados em três grupos de fases da lactação (de 15 a 90, de 91 a 180 e mais de 180 dias de lactação). Os animais utilizados a cada ciclo de pastejo não foram os mesmos; utilizou-se fluxo de animais a fim de se manter vacas nas três fases de lactação. Na Tabela 1, são apresentadas médias de dias em lactação das vacas no início de cada ciclo de pastejo. As vacas de 15 a 90 dias pósparto receberam suplementação com $4 \mathrm{~kg}$ de concentrado por dia.

O delineamento experimental foi em parcelas subsubdivididas, considerando-se a fase de lactação como efeito principal, os piquetes como subparcelas e o dia de ocupação como sub-subparcela. A análise estatística foi feita em separado para cada experimento (tipo de capim), utilizando-se o procedimento PROC GLM do programa SAS (SAS, 1996).

Tabela 1 - Médias de dias em lactação das vacas no início dos ciclos de pastejo

Table 1 - Averages of days in lactation in the beginning of grazing cycles

\begin{tabular}{lcccc}
\hline Ano (Year) & \multicolumn{3}{c}{1999} & 2000 \\
\hline Ciclos de pastejo (Grazing cycles) & $2^{\mathrm{o}}\left(2^{\text {nd }}\right)$ & $3^{\mathrm{o}}\left(3^{\text {rd }}\right)$ & $4^{\mathrm{o}}\left(4^{\text {th }}\right)$ & $1^{\mathrm{O}}\left(1^{\text {st }}\right)$ \\
\hline Capim-elefante (Elephantgrass) & 124 & 164 & 177 & 128 \\
Dias em lactação (Days in lactation) & 124 & 176 & 126 \\
\hline Capim-Tanzânia (Tanzaniagrass) & 138 & 160 & 176 \\
\hline Dias em lactação (Days in lactation) & & & \\
\hline
\end{tabular}




\section{Resultados e Discussão}

Para o capim-elefante cv. Guaçu, não houve efeito do dia de ocupação sobre a produção leiteira, que foi de 10,3 $\pm 3,3$ e 10,4 $\pm 3,2 \mathrm{~kg}$ de leite/vaca/dia para o $1^{\circ}$ e $2^{\circ}$ dias de ocupação, respectivamente
(Tabela 2). Observou-se pequena diferença numérica, com a maior produção de leite no segundo dia de ocupação, em razão da maior disponibilidade de folhas na pastagem no primeiro dia de ocupação, que reflete na produção de leite do dia seguinte.

Tabela 2 - Produção média de leite (kg/vaca/dia) e desvio-padrão (DP), de acordo com o dia de ocupação em pastagem de capim-elefante

Table 2 - Average milk production ( $\mathrm{kg} / \mathrm{cow} / \mathrm{day})$ and standard deviation (SD), according to occupation in days, in elephantgrass

\begin{tabular}{ccc}
\hline Dia de ocupação & $\mathrm{N}^{\mathrm{o}}$ de observações & Produção média de leite $\pm \mathrm{DP}(\mathrm{kg} / \mathrm{vaca} / \mathrm{dia})$ \\
Occupation in days & Number of observations & Average milk production $(\mathrm{kg} /$ cow/day $) \pm S D$ \\
\hline $1^{\mathrm{O}}$ & 211 & $10,3 \pm 3,3$ \\
$2^{\mathrm{O}}$ & 212 & $10,4 \pm 3,2$ \\
\hline
\end{tabular}

Tabela 3 - Massas de forragem inicial e residual e respectivas proporções de caule, folha e material morto, conforme a época de ocupação dos piquetes de capim-elefante

Table 3 - Initial forage mass, stubble and respective rates of stem leaf and dead matter, according to occupation period of elephantgrass paddocks

\begin{tabular}{|c|c|c|c|c|}
\hline Ano (Year) & & $1999^{1}$ & & $2000^{2}$ \\
\hline $\begin{array}{l}\text { Ciclo de pastejo } \\
\text { Grazing cycle }\end{array}$ & $2^{\mathrm{o}}\left(2^{\text {nd }}\right)$ & $3^{\mathrm{o}}\left(3^{\text {rd }}\right)$ & $4^{\mathrm{o}}\left(4^{\text {th }}\right)$ & $1^{\mathrm{o}}\left(1^{s t}\right)$ \\
\hline $\begin{array}{l}\text { Época da avaliação } \\
\text { Evaluation period }\end{array}$ & $\begin{array}{l}\text { Fev e Março } \\
\text { Feb and March }\end{array}$ & $\begin{array}{l}\text { Março e Abril } \\
\text { March and April }\end{array}$ & $\begin{array}{l}\text { Abril e Maio } \\
\text { April and May }\end{array}$ & $\begin{array}{l}\text { Jan e Fev } \\
\text { Jan and Feb }\end{array}$ \\
\hline $\begin{array}{l}\text { Massa de forragem inicial ( } \mathrm{kg} \mathrm{MS} / \mathrm{ha}) \\
\text { Initial forage mass ( } \mathrm{kg} \text { dry matter } / \mathrm{ha})\end{array}$ & $7678^{a}$ & $8534^{\mathrm{a}}$ & $7510^{\mathrm{a}}$ & 5788 \\
\hline $\begin{array}{l}\text { Colmo }(\%) \\
\text { Stem }(\%)\end{array}$ & $35,5^{\mathrm{b}}$ & $36,7^{\mathrm{b}}$ & $47,7^{\mathrm{a}}$ & 41,7 \\
\hline $\begin{array}{l}\text { Colmo }(\mathrm{kg} \mathrm{MS} / \mathrm{ha}) \\
\text { Stem }(\mathrm{kg} \text { dry matter/ha) }\end{array}$ & 2726 & 3132 & 3582 & 2413 \\
\hline $\begin{array}{l}\text { Folha }(\%) \\
\text { Leaf }(\%)\end{array}$ & $54,7^{\mathrm{a}}$ & $45,9^{\mathrm{b}}$ & $31,2^{\mathrm{c}}$ & 40,6 \\
\hline $\begin{array}{l}\text { Folha (kg MS/ha) } \\
\text { Leaf (kg dry matter/ha) }\end{array}$ & 4200 & 3917 & 2343 & 2352 \\
\hline $\begin{array}{l}\text { Material morto }(\%) \\
\text { Dead matter }(\%)\end{array}$ & $9,5^{\mathrm{c}}$ & $17,4^{\mathrm{ab}}$ & $21,1^{\mathrm{a}}$ & 17,7 \\
\hline $\begin{array}{l}\text { Material morto (kg MS/ha) } \\
\text { Dead matter ( } k g \text { dry matter/ha) }\end{array}$ & 729 & 1485 & 1585 & 1023 \\
\hline $\begin{array}{l}\text { Resíduo (kg MS/ha) } \\
\text { Stubble (kg dry matter/ha) }\end{array}$ & $2350^{\mathrm{b}}$ & $1971^{\mathrm{b}}$ & $3090^{\mathrm{a}}$ & 3667 \\
\hline $\begin{array}{l}\text { Colmo }(\%) \\
\text { Stem }(\%)\end{array}$ & $63,6^{\mathrm{a}}$ & $67,4^{\mathrm{a}}$ & $67,0^{\mathrm{a}}$ & 58,6 \\
\hline $\begin{array}{l}\text { Colmo (kg MS/ha) } \\
\text { Stem (kg dry matter/ha) }\end{array}$ & 1495 & 1328 & 2070 & 2149 \\
\hline $\begin{array}{l}\text { Folha }(\%) \\
\text { Leaf }(\%)\end{array}$ & $25,1^{\mathrm{a}}$ & $12,6^{\mathrm{b}}$ & $9,7^{b}$ & 14,5 \\
\hline $\begin{array}{l}\text { Folha }(\mathrm{kg} \mathrm{MS} / \mathrm{ha}) \\
\text { Leaf }(\mathrm{kg} \text { dry matter/ha) }\end{array}$ & 590 & 248 & 300 & 532 \\
\hline $\begin{array}{l}\text { Material morto }(\%) \\
\text { Dead matter }(\%)\end{array}$ & $11,3^{\mathrm{c}}$ & $20,0^{\mathrm{ab}}$ & $23,3^{\mathrm{a}}$ & 26,9 \\
\hline $\begin{array}{l}\text { Material morto (kg MS/ha) } \\
\text { Dead matter ( } k g \text { dry matter/ha) }\end{array}$ & 266 & 394 & 720 & 986 \\
\hline
\end{tabular}

${ }_{1}^{1}$ Fonte: Rosseto (2000), médias seguidas de letras iguais não diferem pelo teste Tukey a $10 \%$.

2 Dados originais.

1 Source: Rosseto (2000), means followed by the same letter do not differ $(P<.10)$ by Tukey test.

2 Original data. 
Em todos os ciclos de pastejo estudados, a proporção inicial de folhas era de 31,2 a $54,7 \%$, caindo para 25,1 a 9,7\% no resíduo após o segundo dia de ocupação (Tabela 3).

Deresz (1994) observou pequenas oscilações na produção média diária de leite por vaca, em capimelefante, conforme o período de ocupação do piquete, de modo que o valor nutritivo da forragem consumida também foi maior no primeiro dia de pastejo, decrescendo com o tempo de ocupação.

Cóser et al. (1999) estudaram três períodos de ocupação para o capim-elefante, ou seja, 1, 3 e 5 dias de ocupação, com 30 dias de descanso, e não encontraram diferença significativa para produção de leite entre os diferentes períodos de ocupação dos piquetes, mas registrou variações diárias, com as menores flutuações no primeiro (10,3 a 10,5 kg/vaca/dia) e as maiores no quinto dia de ocupação, uma vez que houve produção em torno de $10,9 \mathrm{~kg}$ de leite por dia no terceiro e quarto dias de ocupação, caindo para $9,7 \mathrm{~kg}$ de leite no primeiro dia de ocupação. As médias das produções de leite, corrigidas para $4 \%$ de gordura, foram de 9,7; 9,5 e 9,6 no primeiro ano experimental, de 11,$4 ; 11,5$ e 11,4 no segundo ano e de 11,6; 11,5 e 11,4 no terceiro ano para dias 1, 3 e 5 de ocupação, respectivamente, com oferecimento de $2 \mathrm{~kg}$ de concentrado/vaca/dia. Os resultados do $2^{\circ}$ e $3^{\circ}$ anos são maiores que os encontrados neste trabalho.

Quanto à disponibilidade de massa de forragem inicial, Rosseto (2000) encontrou, em mesmo local e época desse experimento, média, para o primeiro ano experimental e durante a estação chuvosa, de $7.781 \mathrm{~kg}$ de MS/ha por ciclo de pastejo, com 44,4\% de folhas, ou seja, $3.454 \mathrm{~kg}$ de MS de folha/ha. As informações por ciclo de pastejo encontram-se na Tabela 3. Esses resultados são superiores aos encontrados por Cóser et al. (1999), de 2.944; 2.641 e $2.912 \mathrm{~kg}$ de MS de folha/ ha para dias 1,3 e 5 de ocupação, respectivamente, com período de descanso de 30 dias.

Balsalobre (1996), avaliando pastejo rotacionado de capim-elefante, registrou valores semelhantes para disponibilidade de matéria seca, durante o verão, com média de $7.978 \mathrm{~kg}$ de MS/ha para três ciclos de pastejo e período de descanso de 45 dias, com média de produção leiteira de 13,06 kg/vaca/dia, com suplementação de $4,2 \mathrm{~kg}$ de concentrado por animal/ dia. Silva et al. (1994) também observaram média de produção de leite em torno de $13 \mathrm{~kg} / \mathrm{vaca} / \mathrm{dia}$, em pastejo rotacionado de capim-elefante anão, enquanto Aroeira et al. (1999) observaram média de 11,4 kg de leite/vaca/dia em pastejo rotacionado de capimelefante, recebendo $2 \mathrm{~kg}$ de concentrado/dia. Os valores encontrados neste trabalho são inferiores aos citados na literatura, possivelmente pelo menor potencial genético das vacas e da menor suplementação com concentrado.

Houve interação $(P<0,01)$ entre a fase da lactação das vacas e os piquetes estudados. Na Tabela 4, constam os resultados referentes à produção diária de leite por vaca, em cada piquete experimental, nas diferentes épocas do ano, com desdobramento para fase da lactação.

Observou-se grande variação nas médias por piquete, ou seja, a produção de leite variou de $12,1 \mathrm{~kg} / \mathrm{vaca} / \mathrm{dia}$ (piquete 1 , em março de 1999) até $8,9 \mathrm{~kg} / \mathrm{vaca} / \mathrm{dia}$ (piquete 19), em janeiro de 2000. Verificou-se diminuição na proporção de folhas presentes na massa de forragem inicial do $2^{\circ}$ para o $4^{\circ}$ ciclo de pastejo de 1999 (Tabela 3), mesmo não havendo redução na quantidade de massa de forragem inicialmente ofertada, o que, provavelmente, explica a queda da média de produção de leite no $4^{\circ}$ ciclo de pastejo de 1999 . A menor produção leiteira nos piquetes 17,18 e 19 , registrada no $2^{\circ}$ ano de estudo, em janeiro de 2000, pode ser explicada pela menor massa de forragem inicial obtida no ano anterior e pela menor porcentagem de folha $(40,64 \%)$ em fevereiro e março de 1999 (54,7\%).

As vacas no início da lactação interagiram positivamente com os piquetes que tinham maior massa de forragem inicial nos ciclos 2, 3 e 4 (Tabela 4 piquetes $n^{\circ} 1$ a 16), com produções de leite $40,16 \%$ superior à média de todas as vacas que ocupavam estes piquetes, enquanto aquelas com período de lactação de 90 a 180 dias apresentaram produções $5,02 \%$ acima da média e as vacas em final de lactação apresentaram produções $14,73 \%$ abaixo da média. Em janeiro e fevereiro de 2000 (piquetes $n^{\circ}$ 17 a 19), quando a massa de forragem inicial foi menor, a produção de leite das vacas no início da lactação foi apenas $9,65 \%$ maior que a média; as vacas de 90 a 180 dias de lactação tiveram produções $2,5 \%$ abaixo da média e as aquelas no final da lactação mantiveram produções semelhantes aos piquetes de $\mathrm{n}^{\mathrm{O}} 1$ a 16 , ou seja, $14,24 \%$ abaixo da média, não havendo diferença significativa entre os três grupos nos piquetes de $n^{0} 17$ a 19 . 
Tabela 4 - Desdobramento da média de produção de leite, em kg/vaca/dia, por fase da lactação em cada piquete experimental de capim-elefante

Table 4 - Unfolding of average milk production ( $\mathrm{kg} / \mathrm{cow} /$ day), considering lactation phase for each experimental elephantgrass paddock

\begin{tabular}{|c|c|c|c|c|c|c|}
\hline \multirow[t]{2}{*}{$\begin{array}{l}\mathrm{N}^{\mathrm{O}} \text { do piquete } \\
\text { Paddock number }\end{array}$} & \multirow[b]{2}{*}{$\begin{array}{c}\text { Ciclo de pastejo } \\
\text { Grazing cycle }\end{array}$} & \multirow[b]{2}{*}{$\begin{array}{c}\text { Mês } \\
\text { Month }\end{array}$} & \multicolumn{3}{|c|}{$\begin{array}{l}\text { Dias de lactação } \\
\text { Days on lactation }\end{array}$} & \multirow[b]{2}{*}{$\begin{array}{l}\text { Média } \\
\text { Mean }\end{array}$} \\
\hline & & & $\begin{array}{l}15 \text { a } 90 \text { dias } \\
15 \text { to } 90 \text { days }\end{array}$ & $\begin{array}{l}91 \text { a } 180 \text { dias } \\
91 \text { to } 180 \text { days }\end{array}$ & $\begin{array}{c}\text { Acima de } 180 \text { dias } \\
>180 \text { days }\end{array}$ & \\
\hline 1 & $2^{\mathrm{o}}$ & $\begin{array}{l}\text { Mar } \\
\text { Mar }\end{array}$ & $16,4^{\mathrm{aA}}$ & $12,3^{\mathrm{bA}}$ & $8,4^{\mathrm{cA}}$ & 12,1 \\
\hline 2 & 1999 & $\begin{array}{l}\text { Mar } \\
\text { Mar }\end{array}$ & $15,9^{\mathrm{aA}}$ & $11,4^{\mathrm{bA}}$ & $7,9^{\mathrm{bA}}$ & 11,8 \\
\hline 3 & & $\begin{array}{l}\text { Mar } \\
\text { Mar }\end{array}$ & $14,9^{\mathrm{aA}}$ & $9,6^{\mathrm{bA}}$ & $8,2^{\mathrm{bA}}$ & 10,7 \\
\hline 4 & & $\begin{array}{l}\text { Mar } \\
\text { Mar }\end{array}$ & $14,9^{\mathrm{aA}}$ & $10,6^{\mathrm{bA}}$ & $8,0^{\mathrm{cA}}$ & 10,9 \\
\hline 5 & $3^{0}$ & $\begin{array}{l}\text { Abr } \\
\text { Apr }\end{array}$ & $13,6^{\mathrm{aA}}$ & $9,8^{\mathrm{abA}}$ & $8,6^{\mathrm{bA}}$ & 9,4 \\
\hline 6 & 1999 & $\begin{array}{l}\text { Abr } \\
\text { Apr }\end{array}$ & $15,6^{\mathrm{aA}}$ & $13,3^{\mathrm{aA}}$ & $10,2^{\mathrm{aA}}$ & 11,5 \\
\hline 7 & & $\begin{array}{l}\text { Abr } \\
\text { Apr }\end{array}$ & $13,4^{\mathrm{aA}}$ & $12,8^{\mathrm{aA}}$ & $9,4^{\mathrm{aA}}$ & 10,6 \\
\hline 8 & & $\begin{array}{l}\text { Abr } \\
\text { Apr }\end{array}$ & $13,8^{\mathrm{aA}}$ & $10,3^{\mathrm{bA}}$ & $8,5^{\mathrm{bA}}$ & 9,5 \\
\hline 9 & & $\begin{array}{l}\text { Abr } \\
\text { Apr }\end{array}$ & $14,9^{\mathrm{aA}}$ & $9,0^{\mathrm{bA}}$ & $8,0^{\mathrm{bA}}$ & 9,0 \\
\hline 10 & & $\begin{array}{l}\text { Maio } \\
\text { May }\end{array}$ & $16,6^{\mathrm{aA}}$ & $11,6^{\mathrm{bA}}$ & $9,7^{\mathrm{bA}}$ & 10,9 \\
\hline 11 & & $\begin{array}{l}\text { Maio } \\
\text { May }\end{array}$ & $14,8^{\mathrm{aA}}$ & $10,7^{\mathrm{bA}}$ & $8,2^{\mathrm{bA}}$ & 9,6 \\
\hline 12 & $4^{\mathrm{O}}$ & $\begin{array}{l}\text { Maio } \\
\text { May }\end{array}$ & $12,6^{\mathrm{aA}}$ & $10,6^{\mathrm{aA}}$ & $9,17^{\mathrm{aA}}$ & 9,9 \\
\hline 13 & 1999 & $\begin{array}{l}\text { Maio } \\
\text { May }\end{array}$ & $13,2^{\mathrm{aA}}$ & $9,8^{\mathrm{bA}}$ & $8,7^{\mathrm{bA}}$ & 9,5 \\
\hline 14 & & $\begin{array}{l}\text { Maio } \\
\text { May }\end{array}$ & $14,9^{\mathrm{aA}}$ & $11,8^{\mathrm{bA}}$ & $9,7^{\mathrm{bA}}$ & 10,8 \\
\hline 15 & & $\begin{array}{l}\text { Maio } \\
\text { May }\end{array}$ & $13,4^{\mathrm{aA}}$ & $10,5^{\mathrm{bA}}$ & $9,1^{\mathrm{bA}}$ & 9,9 \\
\hline 16 & & $\begin{array}{l}\text { Maio } \\
\text { May }\end{array}$ & $13,1^{\mathrm{aA}}$ & $10,1^{\mathrm{abA}}$ & $9,2^{\mathrm{bA}}$ & 9,9 \\
\hline 17 & & $\begin{array}{l}\text { Jan } \\
\text { Jan }\end{array}$ & $11,7^{\mathrm{aA}}$ & $10,6^{\mathrm{aA}}$ & $9,6^{\mathrm{aA}}$ & 10,8 \\
\hline 18 & $\begin{array}{c}1^{\mathrm{o}} \\
2000\end{array}$ & $\begin{array}{l}\text { Jan } \\
\text { Jan }\end{array}$ & $10,8^{\mathrm{aA}}$ & $9,5^{\mathrm{aA}}$ & $7,6^{\mathrm{aA}}$ & 9,7 \\
\hline 19 & & $\begin{array}{l}\text { Jan } \\
\text { Jan }\end{array}$ & $9,7^{\mathrm{aA}}$ & $8,6^{\mathrm{aA}}$ & $8,0^{\mathrm{aA}}$ & 8,9 \\
\hline
\end{tabular}

Médias seguidas de mesma letra minúscula na linha e da mesma letra maiúscula na coluna não diferem $(P<0,05)$ pelo teste Tukey. Means followed the same letter in the same line and in the same column do not differ $(P<.05)$ by Tukey test.

No estudo com capim-tanzânia, houve diferença $(\mathrm{P}<0,01)$ para estádio de lactação das vacas (Tabela 5), mas não houve interação entre estádio da lactação e dia de ocupação.

Houve efeito $(\mathrm{P}<0,05)$ dos dias de ocupação sobre a produção de leite quanto com interação significativa $(\mathrm{P}<0,01)$ para piquete e dia de ocupação. As produ- ções de leite por vaca, por dia de ocupação, em cada piquete experimental, são apresentadas na Tabela 6 , com desdobramento para dia de ocupação.

Apesar de não ter havido diferença estatística, a média para o segundo dia de ocupação foi numericamente maior, provavelmente em razão da maior disponibilidade de forragem do primeiro dia em relação ao 
Tabela 5 - Produção média de leite (kg/vaca/dia) e desvio-padrão (DP), conforme a fase da lactação das vacas, em capim-tanzânia

Table 5 - Average milk production ( $\mathrm{kg} / \mathrm{cow} /$ day) and standard deviation (SD), according to cow lactation phase, grazing Tanzaniagrass

\begin{tabular}{lc}
\hline $\begin{array}{l}\text { Fase da lactação } \\
\text { Lactation phase }\end{array}$ & $\begin{array}{c}\text { Produção de leite } \\
\text { média } \pm \mathrm{DP}(\mathrm{kg} / \mathrm{vaca} / \text { dia })\end{array}$ \\
\hline $\begin{array}{l}\text { Até } 90 \text { dias } \\
\text { Until } 90 \text { days }\end{array}$ & $13,6^{\mathrm{a}} \pm 2,5$ \\
$\begin{array}{l}\text { De } 91 \text { a } 180 \text { dias } \\
\text { From } 91 \text { to } 180 \text { days } \\
\text { Mais de } 180 \text { dias } \\
\text { Over } 180 \text { days }\end{array}$ & $11,1^{\mathrm{b}} 1,7$ \\
\hline
\end{tabular}

Médias, na coluna, seguidas de mesma letra não diferem pelo teste Tukey a $5 \%$.

Means within columns followed by same letter do not differ at $5 \%$ level by Tukey test. segundo e terceiro, principalmente de folhas, aumentando a produção de leite no dia subseqüente (Tabela 7). Cóser et al. (1999), estudando pastagens de capim-elefante com três períodos de ocupação $\left(1^{\circ}\right.$, $3^{\circ}$ e $5^{\circ}$ dias), também encontraram maiores produções de leite no $2^{\circ}$ dia de ocupação.

As produções de leite foram menores no $4^{\circ}$ ciclo de pastejo (piquetes 12 e 13) no final de maio, após o florescimento do capim-tanzânia (Tabela 6). Rosseto (2000), avaliando o desempenho agronômico desta forrageira em mesma época e área experimental deste ensaio, encontraram massa de forragem inicial significativamente menor e proporção reduzida de folhas com aumento na proporção de colmos e material morto após o florescimento deste capim (Tabela 7).

Tabela 6 - Média de produção de leite (kg/vaca/dia) por dia de ocupação dos piquetes experimentais, em pastagem de capim-tanzânia

Table 6 - Average milk production ( $\mathrm{kg} / \mathrm{cow} / \mathrm{day})$ for experimental paddock occupation day for Tanzaniagrass

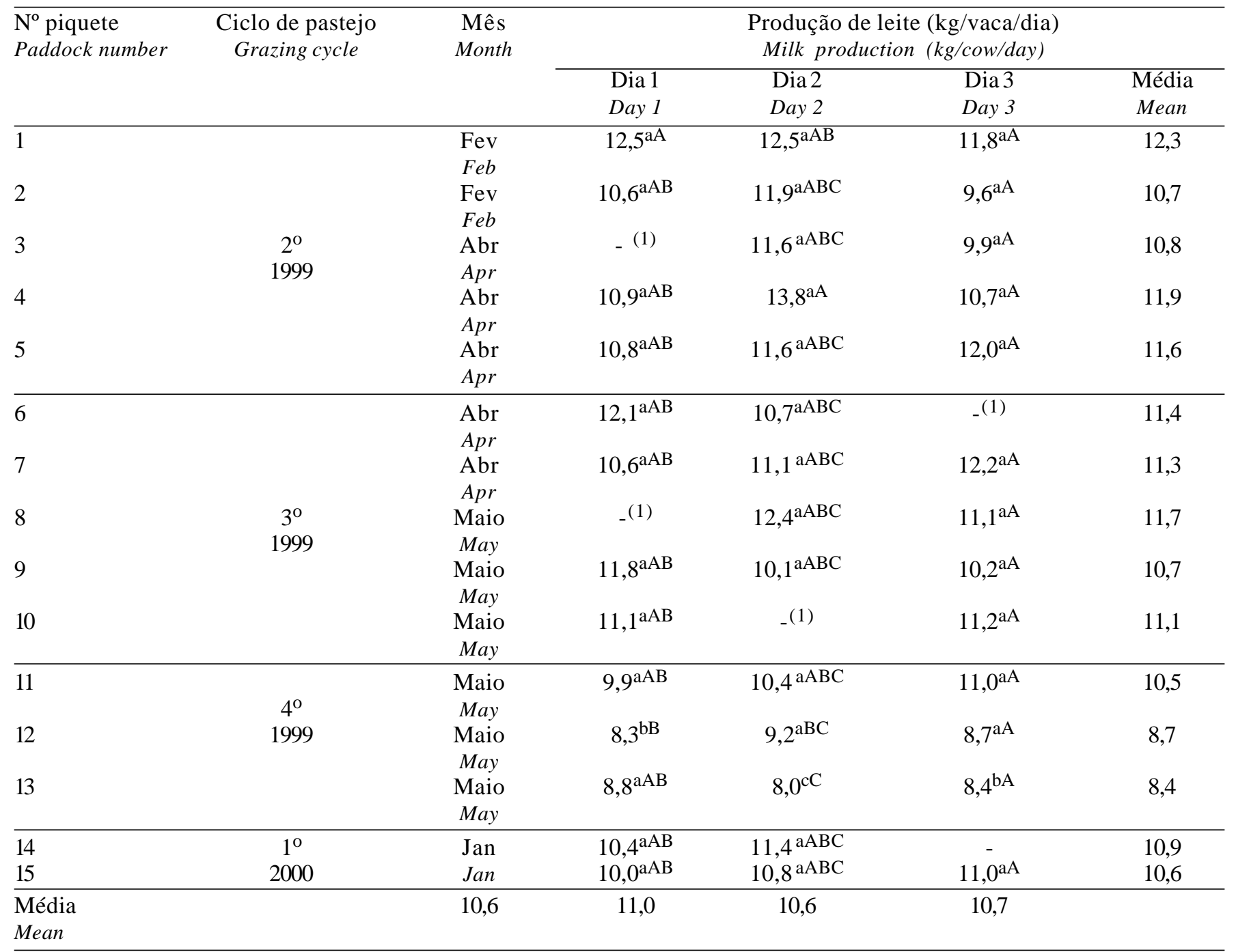

(1) = parcela perdida $((1)=$ lost parcel).

Médias seguidas de mesma letra minúscula na linha e da mesma letra maiúscula na coluna não diferem $(P<0,05)$ teste Tukey.

Means followed the same letter in the same line and in the same column do not differ $(P<.05)$ by Tukey test. 
Tabela 7 - Massas de forragem inicial e residual e respectivas proporções de caule, folha e material morto, conforme a época de ocupação dos piquetes de capim-tanzânia

Table 7 - Initial forage mass, stubble and respective rates of stem leaf and dead matter, according to occupation period of Tanzaniagrass paddocks

\begin{tabular}{|c|c|c|c|c|}
\hline Ano (Year) & & $1999^{1}$ & & $2000^{2}$ \\
\hline $\begin{array}{l}\text { Ciclo de pastejo } \\
\text { Grazing cycle }\end{array}$ & $2^{\mathrm{o}}\left(2^{n d}\right)$ & $3^{o}\left(3^{r d}\right)$ & $4^{\mathrm{o}}\left(4^{\text {th }}\right)$ & $1^{\mathrm{o}}\left(1^{s t}\right)$ \\
\hline Época da avaliação & Fev e Março & Março e Abril & Maio & Jan e Fev \\
\hline Evaluation period & Feb and Mar & Mar and Apr & May & Jan and Feb \\
\hline $\begin{array}{l}\text { Massa de forragem inicial }(\mathrm{kg} \mathrm{MS} / \mathrm{ha}) \\
\text { Initial forage mass ( } \mathrm{kg} \text { dry matter } / \mathrm{ha} \text { ) }\end{array}$ & $5825 \mathrm{a}$ & $5631 \mathrm{a}$ & $4382 b$ & 4823 \\
\hline $\begin{array}{l}\text { Colmo }(\%) \\
\text { Stem }(\%)\end{array}$ & $15,3 b$ & $21,2 b$ & $33,9 \mathrm{a}$ & 35,2 \\
\hline $\begin{array}{l}\text { Colmo (kg MS/ha) } \\
\text { Stem (kg dry matter /ha) }\end{array}$ & 891 & 1194 & 1485 & 1698 \\
\hline $\begin{array}{l}\text { Folha }(\%) \\
\text { Leaf }(\%)\end{array}$ & $70,0 \mathrm{a}$ & $61,3 \mathrm{a}$ & $30,9 b$ & 55,7 \\
\hline $\begin{array}{l}\text { Folha (kg MS/ha) } \\
\text { Leaf (kg dry matter /ha) }\end{array}$ & 4078 & 3452 & 1354 & 2686 \\
\hline $\begin{array}{l}\text { Material morto }(\%) \\
\text { Dead matter }(\%)\end{array}$ & $14,7 b$ & $17,5 b$ & $35,2 \mathrm{a}$ & 9,1 \\
\hline $\begin{array}{l}\text { Material morto (kg MS/ha) } \\
\text { Dead matter (kg dry matter/ha) }\end{array}$ & 856 & 985 & 1542 & 438 \\
\hline $\begin{array}{l}\text { Resíduo (kg MS/ha) } \\
\text { Stubble (kg dry matter/ha) }\end{array}$ & $2292 b$ & $3180 a$ & $2000 \mathrm{~b}$ & 2711 \\
\hline $\begin{array}{l}\text { Colmo }(\%) \\
\text { Stem }(\%)\end{array}$ & $35,9 \mathrm{a}$ & $32,2 \mathrm{a}$ & $38,7 \mathrm{a}$ & 47,3 \\
\hline $\begin{array}{l}\text { Colmo (kg MS/ha) } \\
\text { Stem (kg dry matter/ha) }\end{array}$ & 823 & 1024 & 774 & 1282 \\
\hline $\begin{array}{l}\text { Folha }(\%) \\
\text { Leaf }(\%)\end{array}$ & $36,4 \mathrm{a}$ & $33,4 \mathrm{a}$ & $19,6 b$ & 21,5 \\
\hline $\begin{array}{l}\text { Folha (kg MS/ha) } \\
\text { Leaf ( } k g \text { dry matter/ha) }\end{array}$ & 834 & 1062 & 392 & 583 \\
\hline $\begin{array}{l}\text { Material morto }(\%) \\
\text { Dead matter }(\%)\end{array}$ & $27,7 \mathrm{~b}$ & $34,4 \mathrm{a}$ & $41,7 \mathrm{a}$ & 31,2 \\
\hline $\begin{array}{l}\text { Material morto (kg MS/ha) } \\
\text { Dead matter (kg dry matter/ha) }\end{array}$ & 635 & 1094 & 834 & 846 \\
\hline
\end{tabular}

Médias seguidas de letras iguais não diferem pelo teste Tukey a 10\%.

Means followed by the same letter do not differ $(P<10)$ by Tukey test.

${ }^{1}$ Fonte: Rosseto (2000).

2 Dados originais.

1 Source: Rosseto (2000).

2 Original data.

Santos et al. (1999), estudando capim-tanzânia em diferentes freqüências de pastejo, encontraram, para ciclo de 38 dias e adubação de $400 \mathrm{~kg}$ de N/ha/ano, massa de forragem média disponível de $5.772 \mathrm{~kg}$ de MS/ha sendo maior em janeiro e fevereiro, ao invés de em abril e maio, semelhante aos dados do presente trabalho. A relação folha:colmodiminuiu significativamente dociclode janeiro e fevereiro para o ciclo de abril e maio, com valores de 1,10 e 0,76 respectivamente, confirmando o decréscimo de aparecimento de folhas quando o capim inicia o estádio de florescimento. Corsi \& Santos(1995)também demostraram a estacionalidade de produção do capim-tanzânia, com decréscimo de produção após o florescimento.

\section{Conclusões}

Não houve diferença na produção leiteira nos diferentes dias de ocupação dos piquetes de capim-elefante, demonstrando que dois dias de ocupação por piquete é o manejo adequado à produção leiteira. Os três dias de ocupação, para o capim-tanzânia, interferem na produção leiteira.

As vacas interagem com os sistemas de pastejo rotacionado, influenciando a produção de leite. No capim-elefante, há interação entre fase de lactação e piquete e, no capim-tanzânia, há interação entre dia de ocupação e piquete. 


\section{Literatura Citada}

ARANOVICH, S. O capim colonião e outros cultivares de Panicum maximum Jacq: Introdução e Evolução do Uso no Brasil. In: SIMPÓSIO SOBRE MANEJO DE PASTAGEM, 12., 1995, Piracicaba. Anais... Piracicaba: Fundação de Estudos Agrários Luis de Queiroz, 1995. p.1-20.

AROEIRA, L.J.M.; LOPES, F.C.F.; DERESZ, F. et al. Pasture availability and dry matter intake of lactating crossbred cows grazing elephantgrass (Pennisetum purpureum Schum.). Animal Feed Science and Technology, v.78, p.313-324, 1999.

BALSALOBRE, A.A.M. Desempenho de vacas em lactação sob Pastejo Rotacionado em capim-elefante. Piracicaba: Escola Superior de Agricultura "Luiz de Queiroz", 1996. 127p. Dissertação (Mestrado em Agronomia)- Escola Superior de Agricultura "Luiz de Queiroz", 1996.

CAMARGO, A.C. Produção de leite a pasto. In: SIMPÓSIO SOBRE MANEJO DA PASTAGEM, 13., 1996, Piracicaba. Anais... Piracicaba: Fundação de Estudos Agrários "Luiz de Queiroz”, 1996. p.221-241.

CORSI, M. Manejo de capim-elefante sob pastejo. In: SIMPÓSIO SOBRE MANEJO DA PASTAGEM, 10., 1994, Piracicaba. Anais... Piracicaba: Fundação de Estudos Agrários "Luiz de Queiroz”, 1994. p.143-167.

CORSI, M. Potencial das pastagens para produção de leite. In: PEIXOTO, A.M.; MOURA, J.C.; FARIA, V.P. (Eds.). Bovinocultura leiteira: Fundamentos da exploração racional. Piracicaba: Fundação de Estudos Agrários "Luiz de Queiroz”, 2000. p.399-409.

CORSI, M.; SANTOS, P.M. Potencial de Produção do Panicum maximum. In: SIMPÓSIO SOBRE MANEJO DA PASTAGEM, 12., 1995, Piracicaba. Anais... Piracicaba: Fundação de Estudos Agrários "Luiz de Queiroz", 1995. p.275-304.

CÓSER, A.C.; MARTINS, C.E.; FONSECA, D.M. et al. Efeito de diferentes períodos de ocupação da pastagem de capimelefante sobre a produção de leite. Pesquisa Agropecuária Brasileira, v.34, n.5, p.861-866, 1999.

DAVISON T. M.; COWAN, R.T.; SHEPHERD, R.K. et al. Milk production from cows grazing on tropical grass pastures. 1. Effects of stocking rate and level of nitrogen fertilizer on the pasture and diet. Australian Journal of Experimental Agriculture, v.25, p.505-214, 1985a.

DAVISON T. M.; COWAN, R.T.; SHEPHERD, R.K. et al. Milk production from cows grazing on tropical grass pastures. 2. Effects of stocking rate and level of nitrogen on milk yields and pasture-milk relationship. Australian Journal of Experimental Agriculture, v.25, p.515-223, 1985b.

DERESZ, F.; MOZZER, O.L. Produção de leite em pastagem de Capim-elefante. In: SIMPÓSIO SOBRE CAPIMELEFANTE,1990, Juiz de Fora. Anais... Coronel Pacheco: Embrapa Gado de Leite, 1990. p.155-172.

DERESZ, F. Manejo de pastagem de capim elefante para produção de leite e carne. In: SIMPÓSIO SOBRE CAPIM-ELEFANTE, 2., 1994, Coronel Pacheco. Anais... Coronel Pacheco: Embrapa Gado de Leite, 1994. p.116-137.
EUCLIDES, V.P.B. Valor alimentício de espécies forrageiras do gênero Panicum. In: PEIXOTO, A.M.; MOURA, J.C.; FARIA, V. P. (Eds.). Manejo de pastagem. Piracicaba: Fundação de Estudos Agrários Luis de Queiroz, 1995. p.1-20.

LUCCI, C.S.; ROCHA, G.L.; FREITAS, E.A.N. Produção de leite em regime exclusivo de pastagens de capim fino e napier. Boletim de Indústria Animal, v.29, n.1, p.45-51, 1972.

LUCCI, C.S., ROCHA, G.L.; KALIL, E.B. Produção de leite em pastos de napier (Pennisetum purpureum). II. Boletim de Indústria Animal, v.26 n.único, p.165-172, 1969.

OLIVO, C.J.; MOREIRA, J.C.; BARRETO, I.L. et al. Utilização de pastagens de capim-elefante e capim-setária como base da alimentação de vacas em lactação, durante o verão. Revista da Sociedade Brasileira de Zootecnia, v.21, n.3, p.347-352, 1992.

ROSSETO, F.A.A. Desempenho agronômico de plantas forrageiras em dois sistemas de produção de leite baseados no uso de pastagens de capim elefante cv. Guaçu (Pennisetum purpureum) e capim-tanzânia (Panicum maximum).Piracicaba: Escola Superior de Agricultura "Luiz de Queiroz”, 2000, 174p. Dissertação (Mestrado em Agronomia) - Escola Superior de Agricultura "Luiz de Queiroz", 2000.

SANTOS, P.M.; CORSI, M.; BALSALOBRE, M.A.A. Efeito da frequiência de pastejo e da época do ano sobre a produção e a qualidade em Panicum maximum cvs. Tanzânia e Mombaça. Revista Brasileira de Zootecnia, v.28, n.2, p.4244-4249, 1999.

STATISTICAL ANALYSIS SYSTEM - SAS. User's guide: statistics. Cary: 1996. 965p.

SILVA, D.S.; GOMIDE, J.A.; QUEIROZ, A.C. Pressão de pastejo em pastagem de capim-elefante anão (Pennisetum purpureum Schum. Cv Mott). 2. Efeito sobre o valor nutritivo, consumo de pasto e produção de leite. Revista da Sociedade Brasileira de Zootecnia, v.23, n.3, p.453-464, 1994.

TEIXEIRA, E.I.; MATTOS, W.R.S.; CAMARGO, A.C. et al. Avaliação da produção e utilização de uma pastagem de capim Tobiatã (Panicum maximum cv. Tobiatã) sob pastejo rotacionado. Ciência Agrícola, v.56, n.2, p.349-355, 1999.

VEIGA, J.B. Utilização do capim-elefante sob pastejo. In: SIMPÓSIO SOBRE CAPIM-ELEFANTE, 1990, Coronel Pacheco. Anais... Coronel Pacheco: Embrapa Gado de Leite, 1990. p.133-154.

VELOSO, L.; FREITAS, E.A.N. Produção de leite com vacas manejadas em pastos de gramíneas e pasto consorciados (gramíneas + leguminosas). Zootecnia, v.11, p.177-182, 1973. 